\title{
A NEW VALIDATED STABILITY-INDICATING DIRECT HIGH-PERFORMANCE LIQUID CHROMATOGRAPHY METHOD FOR THE DETERMINATION OF ROSIGLITAZONE ENANTIOMERS IN THE PRESENCE OF ITS DEGRADATION PRODUCTS
}

\author{
BYRAN GOWRAMMA ${ }^{1 *}$, SUBRAMANIYAN NAIYANAR MEYYANATHAN ${ }^{2}$, BASAWAN BABU², \\ NAGAPPAN KRISHNAVENI ${ }^{2}$
}

\begin{abstract}
${ }^{1}$ Department of Pharmaceutical Chemistry, JSS College of Pharmacy, (JSS Academy of Higher Education and Research, Mysuru) Udhagamandalam, Nilgiris, Tamil Nadu, India. ${ }^{2}$ Department of Pharmaceutical Analysis, JSS College of Pharmacy, (JSS Academy of Higher Education and Research, Mysuru) Udhagamandalam, Nilgiris, Tamil Nadu, India. Email: gowrammab@rediffmail.com
\end{abstract}

Received: 26 January 2018, Revised and Accepted: 14 November 2018

ABSTRACT

Objective: In the present study, an isocratic chiral reverse-phase high-performance liquid chromatography method was developed and the resolution of the drug and complete separation from its degradation products were successfully achieved.

Methods: An isocratic method developed with a Phenomenex Lux $5 \mu$ Cellulose 1 (150 mm×4.6 mm i.d., $5 \mu$ ) using UV detector at wavelength of $220 \mathrm{~nm}$, with a mobile phase consisting of methanol:0.1\% diethylamine (60:40\% v/v) and a flow rate of $1 \mathrm{ml} / \mathrm{min}$. The drug was subjected to alkaline, acidic, neutral, oxidative, and photolytic to apply stress conditions. The stressed samples were analyzed by the proposed method.

Results: The described method was linear over the range of 3-7 $\mu \mathrm{g} / \mathrm{ml}$ for R-enantiomer and 9-21 $\mu \mathrm{g} / \mathrm{ml}$ of S-enantiomer, respectively. The limit of detection and limit of quantification of $\mathrm{R}$ and $\mathrm{S}$ enantiomers were found to be $0.56 \mu \mathrm{g} / \mathrm{ml}$ and $0.18 \mu \mathrm{g} / \mathrm{ml}$, respectively.

Conclusion: The method provides good sensitivity and excellent precision and reproducibility. The developed method can be applied in the quality control of drug products.

Keywords: Stability-indicating method, Validation, Chiral, Rosiglitazone.

(C) 2019 The Authors. Published by Innovare Academic Sciences Pvt Ltd. This is an open access article under the CC BY license (http://creativecommons. org/licenses/by/4. 0/) DOI: http://dx.doi.org/10.22159/ajpcr.2019.v12i3.24960

\section{INTRODUCTION}

The stability-indicating assay is a method applied to ensure the stability of a drug. The presence of impurities and degradation products can change chemical, pharmacological, and toxicological properties of drugs having significant impact on their quality and safety. Since drugs are, especially, sensitive to environmental factors, strict storage conditions are necessary [1]. The ICH guideline Q1A on stability testing of new drug substances suggests that the testing of those features which are susceptible to change during storage and are likely to influence quality, safety, and efficacy must be done by validated stability-indicating methods. Stress testing should be carried out on a drug to establish its inherent stability characteristics and to support the suitability of the proposed analytical method. It is also suggested that stress testing should include the effects of temperature, susceptibility across a wide range of $\mathrm{pH}$ values, as well as oxidative and photolytic conditions [2].

Like stability-indicating study, the enantioseparation has a great impact on the pharmacological and toxicological properties of chiral drugs in terms of the control of individual variability in clinical responses between the enantiomers. A prerequisite for progress in acquiring knowledge of stereo-specific pharmacodynamic and pharmacokinetics of optical isomers is the development of an enantioselective analytical methodology. High-performance liquid chromatography (HPLC) is one of the famous analytical techniques commonly employed in conducting stability studies and in chiral separation [3-4]. HPLC has gained popularity due to its high-resolution capacity, speed, sensitivity, and specificity. Separation of enantiomers by HPLC can be achieved using either chiral stationary phases (CSPs) or chiral additives to the mobile phase. The most common HPLC approach for resolving enantiomers involves the use of CSPs [4-9].
Rosiglitazone hydrochloride is chemically known as rosiglitazone (RS)5-[4-(2-[methyl (pyridin-2-yl)amino]ethoxy)benzyl]thiazolidine-2,4dione (Fig. 1) has an oral hypoglycemic agent used in Type II diabetes. It targets insulin resistance. It is highly selective and potent against for the peroxisome proliferators-activated receptor (PPAR)-gamma. The activation of PPAR- $\gamma$ nuclear receptor receptors is said to regulate the transcription of insulin-responsive genes, involved in the control of glucose production, transport, and utilization $[10,11]$.

From the literature review, it is observed that no stability-indicating assay methods (SIAMs) for the determination of rosiglitazone enantiomers was available keeping in the view of susceptibility of rosiglitazone enantiomers under variety of conditions. It was felt that SIAMs that separate the drug enantiomers from their degradation products formed need to be developed. Hence, the aim of this study is to establish a validated stability-indicating chiral HPLC method for rosiglitazone enantiomers using Phenomenex Lux Cellulose 1 column. None of the reported analytical methods described stability-indicating method for the reverse-phase (RP) chiral HPLC method of rosiglitazone enantiomers in the presence of its degradation products. To the best of our knowledge, this is the first report of stability-indicating method for the chiral determination of rosiglitazone enantiomers.

\section{RESEARCH METHODS}

Tools and materials

Materials

Solvents and chemicals

Rosiglitazone RS (98.67\%) was obtained as gift sample from Sun Pharmaceutical Industries Ltd., Bharuch, Gujarat, India. Methanol, 
acetonitrile, and isopropyl alcohol (HPLC grade) were supplied by Merck, diethylamine and trifluoroacetic acid from S.D. Fine Chemicals. Commercially available tablets rosiglitazone were purchased commercially from the local market, Udhagamandalam, Tamil Nadu, India.

\section{Instrumentation}

Chromatographic separation and quantitative determination were performed using an HPLC system, from Shimadzu (Kyoto, Japan) equipped with LC-10 AT-VP solvent data station delivery system, an SPD M10 A UV detector, LC-2010 an HT autosampler with loop volume of $100 \mu \mathrm{L}$, and the class VP data station was used. The stationary phase Phenomenex Lux Cellulose 1 ( $\times 250$ 4.6mm i.d, $5 \mu$ ) column was used for the enantiomeric separation of rosiglitazone and the mobile phase consists methanol:0.1\% diethylamine $(60: 40 \% \mathrm{v} / \mathrm{v})$ and a flow rate of $1 \mathrm{ml} / \mathrm{min}$ with detection wavelength at $220 \mathrm{~nm}$.

\section{Selection of wavelength}

About $10 \mu \mathrm{g} / \mathrm{ml}$ solution of rosiglitazone in methanol was prepared and recorded UV spectrum by scanning the solution in the range of $200 \mathrm{~nm}-400 \mathrm{~nm}$. Wavelength of $220 \mathrm{~nm}$ was selected from UV spectrum (Fig. 2) at which the maximum absorbance showed for rosiglitazone hydrochloride.

\section{Preparation of stock and standard solution}

Each $10 \mathrm{mg}$ of $\mathrm{R}$ and $\mathrm{S}$ form of rosiglitazone was taken into $10 \mathrm{ml}$ volumetric flasks. To this, $5 \mathrm{ml}$ of methanol was added and sonicated for 10 min until a clear solution was obtained. The resulting solution was made up to $10 \mathrm{ml}$ with methanol (standard solution A). These stock solutions were stored in light-resistant containers. Aliquots of mixed standards of rosiglitazone R and S (10 $\mathrm{\mu g} / \mathrm{ml})$ were prepared in mobile phase for analysis. The standard solution was prepared and injected and the chromatogram was recorded (Fig. 3).

\section{Forced degradation studies}

Pure active pharmaceutical ingredient of rosiglitazone hydrochloride was forced under various stress conditions to conduct degradation

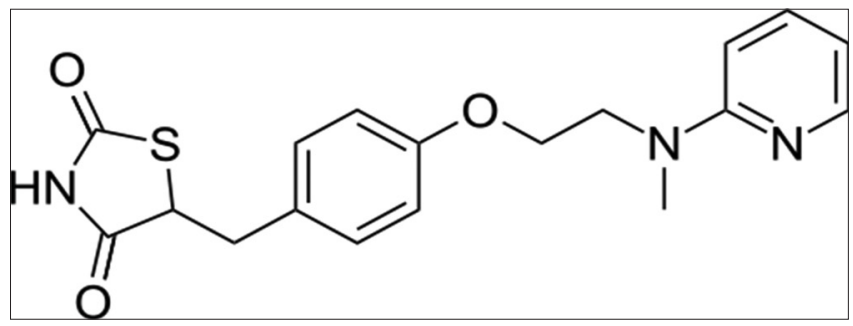

Fig. 1: Chemical structure of rosiglitazone

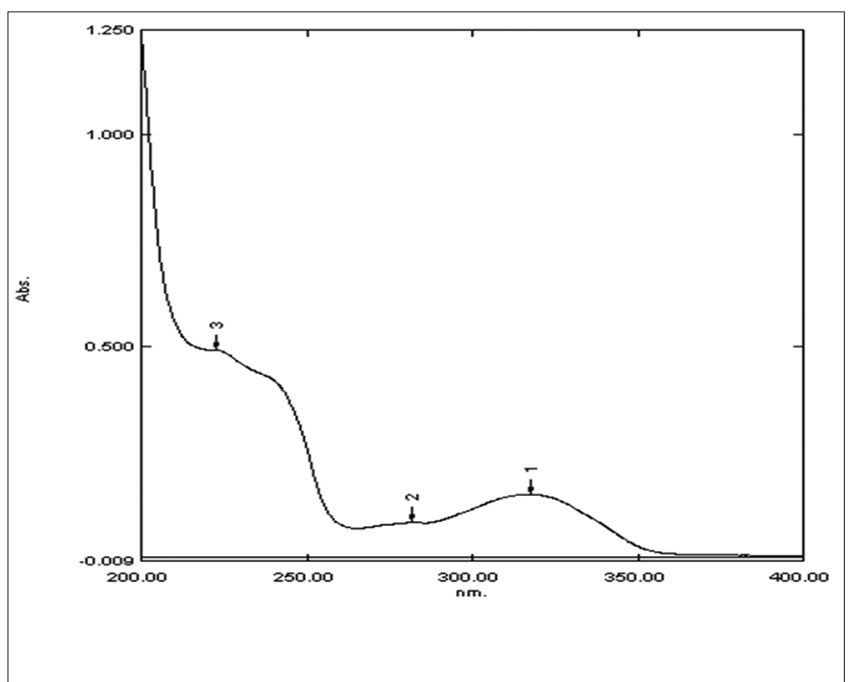

Fig. 2: UV spectrum of rosiglitazone (abs=absorbance) studies. The forced degradation of the drugs can be achieved by the following stress conditions:

- Hydrolysis under acidic and alkaline conditions

- Hydrolysis under neutral conditions

- Oxidative degradation

- Photolytic degradation.

Rosiglitazone standard is freely soluble and stable in methanol, so methanol was used as a cosolvent in all the forced degradation studies. The solutions were prepared by dissolving the active pharmaceutical ingredient in small volume of methanol and later diluted with aqueous sodium hydroxide, aqueous hydrochloric acid, distilled water, and aqueous hydrogen peroxide to achieve a concentration of $10 \mu \mathrm{g} / \mathrm{ml}$ of rosiglitazone photodegradation study also performed using methanol.

\section{Base degradation}

About $1 \mathrm{ml}$ of standard stock solution was taken into $10 \mathrm{ml}$ volumetric flask and volume was made up with $0.1 \mathrm{~N}$ sodium hydroxide. The solution was kept at room temperature for $2 \mathrm{~h}$. The samples were analyzed after $2 \mathrm{~h} .1 \mathrm{ml}$ of sample was diluted to $10 \mathrm{ml}$ with mobile phase. The samples were injected and the chromatograms were recorded (Fig. 4). Further, to increase the extent of degradation, the standard solution was treated with $1 \mathrm{M}$ sodium hydroxide and the solution was kept at room temperature for $24 \mathrm{~h} .1 \mathrm{ml}$ aliquots of the samples were withdrawn at 1 , $2,4,8,12$, and $24 \mathrm{~h}$. The samples were further diluted and analyzed by the optimized chromatographic conditions. The solutions were injected and the chromatograms were recorded.

\section{Acid degradation}

About $1 \mathrm{ml}$ of standard stock solution was taken into $10 \mathrm{ml}$ volumetric flask and volume was made up with $0.1 \mathrm{~N}$ hydrochloric acid. The solution

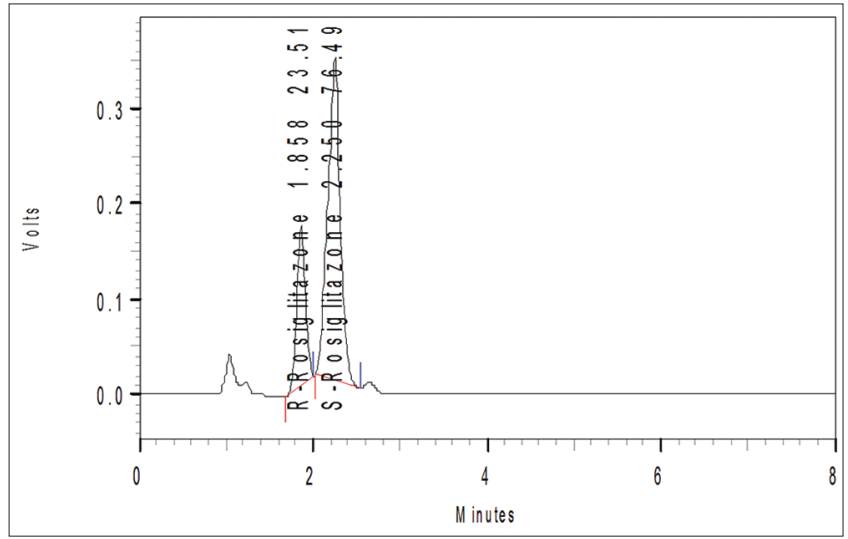

Fig. 3: Typical high-performance liquid chromatography standard chromatogram of rosiglitazone

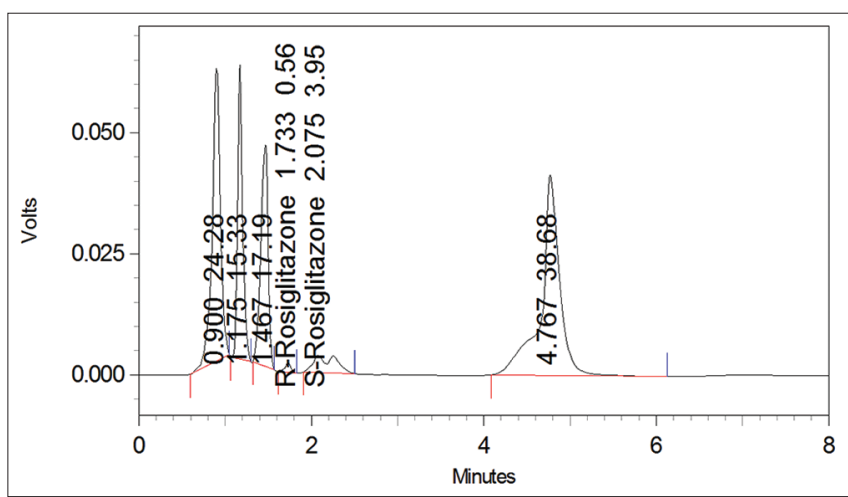

Fig. 4: Typical high-performance liquid chromatography chromatogram of basic degradation sample of $R$ and $S$ rosiglitazone with1 $\mathrm{N} \mathrm{NaOH}$ at $0 \mathrm{~h}$ 
was kept at room temperature for $2 \mathrm{~h}$. The samples were analyzed after $2 \mathrm{~h}$. $1 \mathrm{ml}$ of sample was diluted to $10 \mathrm{ml}$ with mobile phase. The samples were injected and the chromatograms were recorded. Further, to increase the extent of degradation, the standard solution was treated with $1 \mathrm{M}$ hydrochloric acid and the solution was kept at room temperature for $24 \mathrm{~h} .1 \mathrm{ml}$ aliquots of the samples were withdrawn at 1 , $2,4,8,12$, and $24 \mathrm{~h}$. The samples were further diluted and analyzed by the optimized chromatographic conditions. The solutions were injected and the chromatograms were recorded.

\section{Neutral degradation}

About $1 \mathrm{ml}$ of $1000 \mu \mathrm{g}$ rosiglitazone sample was taken into $10 \mathrm{ml}$ volumetric flask and diluted with Milli $\mathrm{Q}$ water, contents were mixed well. The solution was kept at room temperature for $24 \mathrm{~h}$ and $1 \mathrm{ml}$ aliquots of the solutions were withdrawn at 2, 4, 6, 8, 12, and $24 \mathrm{~h}$. $1 \mathrm{ml}$ of this solution was taken into $10 \mathrm{ml}$ volumetric flask and then diluted to $10 \mathrm{ml}$ with mobile phase. The solutions were injected and the chromatograms were recorded (Fig. 5).

\section{Oxidative degradation}

About $1 \mathrm{ml}$ of $1000 \mu \mathrm{g}$ rosiglitazone sample was taken into $10 \mathrm{ml}$ volumetric flask and diluted with $30 \%$ hydrogen peroxide, contents were mixed well. The solution was kept at room temperature for $24 \mathrm{~h}$ and $1 \mathrm{ml}$ aliquots of the solutions were withdrawn at 2, 4, 6, 8, 12, and $24 \mathrm{~h} .1 \mathrm{ml}$ of this solution was taken into $10 \mathrm{ml}$ volumetric flask and then diluted to $10 \mathrm{ml}$ with mobile phase. The solutions were injected and the chromatograms were recorded.

\section{Photolytic degradation}

About $1 \mathrm{ml}$ of $1000 \mu \mathrm{g}$ rosiglitazone sample was taken into $10 \mathrm{ml}$ volumetric flask, and diluted with mobile phase and kept in UV chamber for $24 \mathrm{~h}$, and $1 \mathrm{ml}$ aliquots of the solutions were withdrawn at 2, 4, 6, 8,12 , and $24 \mathrm{~h} .1 \mathrm{ml}$ of this solution was taken into $10 \mathrm{ml}$ volumetric flask and then diluted to $10 \mathrm{ml}$ with mobile phase. The solutions were injected and the chromatograms were recorded.

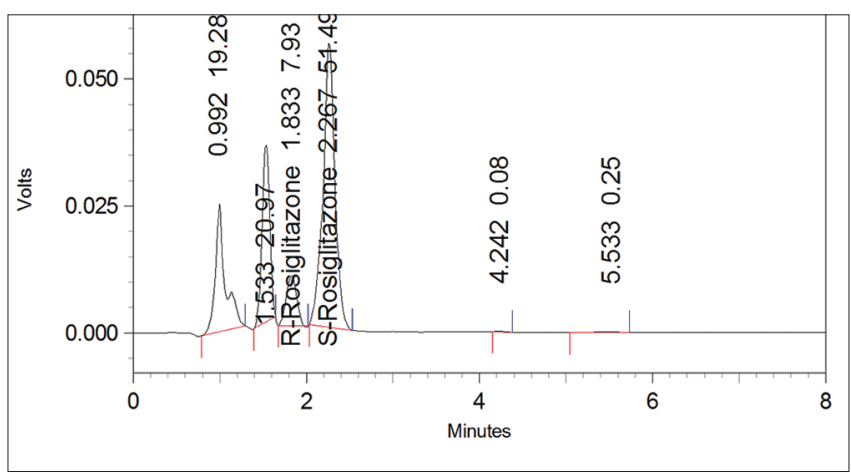

Fig. 5: Typical high-performance liquid chromatography chromatogram of neutral degradation sample of $R$ and $S$ rosiglitazone with neutral at $24 \mathrm{~h}$

\section{RESULTS AND DISCUSSION}

\section{Optimization of chromatographic conditions}

HPLC method carried out in this study, aimed at developing a chromatographic system, capable of eluting and resolving rosiglitazone enantiomers from their degradation products. The preliminary investigations were directed toward the effect of various factors on the system. The factors assessed include the type of column and the composition of mobile phase. The samples were initially analyzed using a mobile phase consisting of ACN, $20 \mathrm{mM}$ ammonium bicarbonate (pH: 4.6) adjusted with trifluoroacetic acid, and methanol (55:15:30 v/v/v). Under this condition, no separation of rosiglitazone enantiomers was achieved. Partial separation was observed when triethylamine was added to the mobile phase. To improve the peak shape, diethylamine was used instead of triethylamine. Various percentages of methanol and diethylamine were tested to achieve the optimum separation of the two enantiomers.

Finally, the optimized chromatographic conditions are with the mobile phase consisting of methanol:0.1\% diethylamine $(60: 40 \% \mathrm{v} / \mathrm{v})$ on a Phenomenex Lux Cellulose $1(250 \times 4.6 \mathrm{~mm}$ i.d, $5 \mu)$ column gave a satisfactory separation of rosiglitazone enantiomers and their degradation products formed under various stress conditions. The detection was carried out under $220 \mathrm{~nm}$ with flow rate of $1 \mathrm{ml} / \mathrm{min}$. The retention times of $\mathrm{R}$ enantiomers and $\mathrm{S}$ were observed to be 1-8 $\mathrm{min}$ and $2.2 \mathrm{~min}$, respectively.

\section{Forced degradation studies}

HPLC studies of samples obtained on stress testing of rosiglitazone enantiomers under different conditions suggested the following degradation behaviors (Table 1). Complete degradation of R-rosiglitazone and $\mathrm{S}$ was found with $1 \mathrm{~N} \mathrm{NaOH}$ and $30 \%$ hydrogen peroxide (Fig. 4) around 24.96, 24.97, and 28.79, 34.80\% of degradation after $24 \mathrm{~h}$. Rosiglitazone enantiomers were found to be stable under acidic condition; around $9.46 \%$ and $9.89 \%$ were degraded through $24 \mathrm{~h}$, and the main analyte was eluted at 1.8 and 2.2 min during HPLC analysis. In neutral stress condition, only $4.24 \%$ and $5.57 \%$ were degraded through $24 \mathrm{~h}$ as compared to standard drug (Fig. 5). In photodegradation, $0.79 \%$ and $2.05 \%$ were degraded through $24 \mathrm{~h}$, respectively. The drug was degraded more in alkaline and oxidation condition.

\section{Method validation}

RP-HPLC method was validated according to the ICH guidelines. The calibration curves of enantiomer I and enantiomer II were linear in the range of $56-84 \mu \mathrm{g} / \mathrm{ml}$ and $52-78 \mu \mathrm{g} / \mathrm{ml}$, respectively. The regression equation and correlation coefficient are shown in Fig. 6. The precision of the method was demonstrated by reproducibility studies. The mean, standard deviation, and percentage relative standard deviation (RSD) were calculated. The percentage RSD values were found to be $<2 \%$ revealed that the method was precise. The accuracy of the optimized method was determined by absolute recovery experiments. An analysis of the results showed that the percentage recovery values were close to $100 \%$, thus

Table 1: Results of stress degradation studies of rosiglitazone enantiomers by HPLC

\begin{tabular}{|c|c|c|c|c|c|c|c|c|c|c|c|}
\hline \multirow[t]{2}{*}{ S. No. } & \multirow[t]{2}{*}{ Time (h) } & \multicolumn{2}{|c|}{$\begin{array}{l}\text { Basic hydrolysis } \\
\text { (\% degradation) } 1 \\
\mathrm{~N} \mathrm{NaOH}\end{array}$} & \multicolumn{2}{|c|}{$\begin{array}{l}\text { Acid hydrolysis } \\
\text { (\% degradation) } \\
1 \text { N HCL }\end{array}$} & \multicolumn{2}{|c|}{$\begin{array}{l}\text { Neutral degradation } \\
\text { (\% degradation) } \mathrm{H}_{2} \mathrm{O}\end{array}$} & \multicolumn{2}{|c|}{$\begin{array}{l}\text { Oxidative degradation } \\
\text { (\% degradation) } 30 \% \\
\mathrm{H}_{2} \mathrm{O}_{2}\end{array}$} & \multicolumn{2}{|c|}{$\begin{array}{l}\text { Photodegradation } \\
\text { (\% degradation) }\end{array}$} \\
\hline & & I & II & I & II & I & II & I & II & I & II \\
\hline 1 & 0 & 0 & 0 & 0 & 0 & 0 & 0 & 0 & 0 & 0 & 0 \\
\hline 2 & 2 & 22.83 & 28.51 & 2.57 & 2.33 & 0.55 & 0.89 & 23.40 & 29.04 & 0 & 0 \\
\hline 3 & 4 & 22.97 & 28.87 & 3.46 & 4.57 & 0.88 & 1.35 & 24.01 & 30.31 & 0 & 0 \\
\hline 4 & 6 & 23.05 & 29.17 & 4.69 & 5.13 & 1.33 & 2.57 & 24.61 & 31.48 & 0 & 0 \\
\hline 5 & 8 & 25.36 & 26.43 & 5.42 & 7.55 & 2.55 & 3.55 & 24.71 & 33.11 & 0 & 0 \\
\hline 6 & 12 & 25.88 & 28.66 & 7.98 & 9.35 & 3.33 & 5.24 & 24.86 & 34.12 & 0.19 & 0.30 \\
\hline 7 & 24 & 24.96 & 28.79 & 9.46 & 9.89 & 4.24 & 5.57 & 24.97 & 34.80 & 0.79 & 2.05 \\
\hline
\end{tabular}

HPLC: High-performance liquid chromatography 


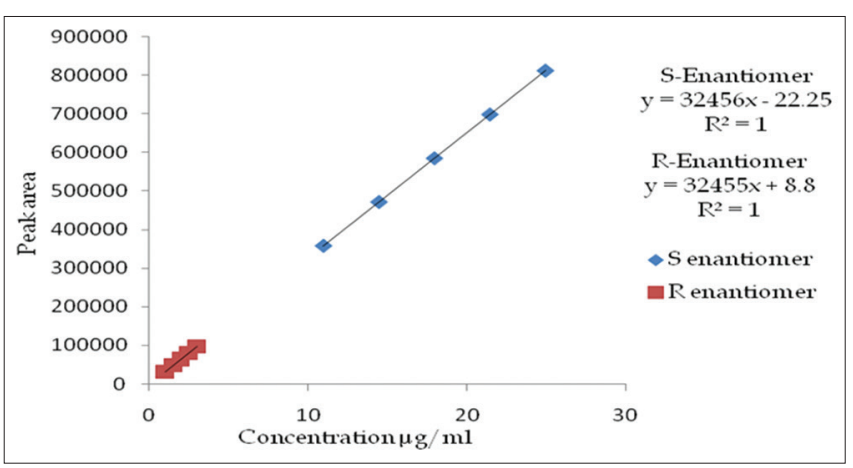

Fig. 6: Calibration curve of $R$ and $S$ rosiglitazone by highperformance liquid chromatography

Table 2: System suitability studies for the determination of $R$ rosiglitazone and $S$ rosiglitazone

\begin{tabular}{llll}
\hline S. No & Parameters & R Enantiomer & S Enantiomer \\
\hline 1. & Linearity range & $3-7 \mu \mathrm{g} / \mathrm{mL}$ & $9-21 \mu \mathrm{g} / \mathrm{mL}$ \\
2. & Regression equation $\mathrm{y}=\mathrm{mx}+\mathrm{c}=32455 \mathrm{x}-8.8$ & $\mathrm{Y}=32456 \mathrm{x}-22.25$ \\
3. & Correlation coefficient & 1.0 & 1.0 \\
4. & Theoretical plate $/$ meter & 40074 & 45503 \\
5. & Resolution factor & 0.6 & \\
6. & Asymmetric factor & 1.02 & 1.01 \\
7. & LOD $(\mu \mathrm{g} / \mathrm{mL})$ & 0.596 & 0.596 \\
8. & LOQ $(\mu \mathrm{g} / \mathrm{mL})$ & 1.86 & 1.86 \\
\hline
\end{tabular}

LOD: Limit of detection, LOQ: Limit of quantification

establishing that the developed method is accurate and reliable. Detection limit and quantification limit of enantiomer I and II were found to be $0.30 \mu \mathrm{g} / \mathrm{ml}$ and $0.90 \mu \mathrm{g} / \mathrm{ml}$ and $0.32 \mu \mathrm{g} / \mathrm{ml}$ and $0.97 \mu \mathrm{g} / \mathrm{ml}$, respectively. No marked changes in the chromatograms occurred on changing the instrument. Chromatographic conditions indicated that the developed method was rugged and robust. The column efficiency, resolution, and the peak asymmetry were calculated for the standard solutions. Signal-tonoise ratio of the 3 and 10 is generally considered as limit of detection and limit of quantification, respectively, Table 2.

\section{CONCLUSION}

A highly specific stability-indicating chiral HPLC method was developed for the $1^{\text {st }}$ time to quantify the rosiglitazone enantiomers in the presence of degradation products. The enantioseparation was carried out by the use of cellulose-based chiral column. The method provides good sensitivity and excellent precision and reproducibility. The method was highly selective, where degradation products and coformulated compounds did not interfere. The proposed method was successfully applied in pharmaceutical preparations.

\section{ACKNOWLEDGMENTS}

The authors are grateful to His Holiness Jagadguru Sri Sri Shivarathri Deshikendra Mahaswamigalavaru of Sri Suttur Mutt, Mysore, for his blessings and the facilities provided to complete the research work successfully.

\section{AUTHORS' CONTRIBUTIONS}

Dr. B. Gowramma has performed the work presented here. Dr. S. N. Meyyanathan has guided this project. Dr. B. Babu contributed to the data analysis and interpretation. Dr. N. Krishnaveni contributed to some part of the discussion.

\section{CONFLICTS OF INTEREST}

This study has no conflicts of interest to be declared.

\section{REFERENCES}

1. Ahuja S. Impurities Evaluation of Pharmaceuticals. New York: Marcel Dekker Inc.; 1998.

2. Ahuja S, Alsante, KM. Handbook of Isolation and Characterisation of Impurities in Pharmaceuticals. San Diego, USA: Academic Press; 2003.

3. Baaske DM, DeMay JF, Latona CA, Mirmira S, Sigvardson KW. Stability of nicardipine hydrochloride in intravenous solutions. Am J Health Syst Pharm 1996;53:1701-5.

4. Nagappan K, Yamjala K, Sathyaseelan M, Byran G. Stability evaluation of tartrazine by liquid chomatography-diode array detector and highresolution electron spray ionization quadrupole time-offlight mass spectrometry/mass spectrometry analysis. Asian J Pharm Clin Res 2017;10:295-9.

5. Daraghmeh N, Al-Omari M, Badwan AA, Jaber AM. Determination of sildenafil citrate and related substances in the commercial products and tablet dosage form using HPLC. J Pharm Biomed Anal 2001;25:483-92.

6. Pettersson C, Persson B. In: Katz E, Eksteen R, Schoenmakers P, Miller N, editors. Handbook of HPLC. New York: Marcel Dekker; 1998. p. 669.

7. Subramanian G, editors. A Practical Approach to Chiral Separations by Liquid Chomatography. Weinheim, Germany: Verlagsgesellschaft MBH; 1994.

8. Gowramma B, Meyyanathan SN. Stability indicating chiral HPLC method for the estimation of pioglitazone enantiomers in pharmaceutical formulation. Asian J Pharm Clin Res 2015;8:63-6.

9. Singh S, Baksh M. Development of validated stability-indicating assay methods-critical review. J Pharm Biomed Anal 2002;28:1011.

10. International Conference on Harmonisation. Stability Testing of New Drug Substances and Products Q1A. Geneva: International, Conference on Harmonization, IFPMA; 1993.

11. Ritchie JA, Truelove SC. Comparison of various treatments for irritable bowel syndrome. Br Med J 1980;281:1317-9. 